\title{
Práticas pedagógicas e ensino integrado
}

\author{
Ronaldo Marcos de Lima Araujo \\ Universidade Federal do Pará \\ Gaudêncio Frigotto \\ Universidade do Estado do Rio de Janeiro
}

\section{Resumo}

Trata-se, nesse artigo, de práticas pedagógicas articuladas ao projeto de ensino integrado. Por meio de pesquisa bibliográfica e tendo como referência principal educadores marxistas, em particular, Pistrak (2009), problematizam-se possíveis soluções apenas didáticas para o projeto de ensino integrado e afirma-se que o desenvolvimento de práticas pedagógicas integradoras requer, principalmente, soluções ético-políticas. Sustenta-se que o essencial é vincular o ensino ao trabalho real dos alunos, valorizando a sua auto-organização e requerendo uma atitude humana transformadora. Com base nessas referências, são sistematizadas orientações para ação didática integradora valorizando o trabalho coletivo, a problematização e auto-organização como estratégias principais para a formação dos sujeitos solidários, críticos e autônomos.

Palavras-chave: Ensino médio. Ensino integrado. Práticas pedagógicas.

\section{Pedagogical practices as a challenge for integrated education}

\begin{abstract}
The article is about pedagogical practices coordinated the integrated education project. Through literature review and considering primary Marxist educators, particularly Pistrak (2009), problematizes potential solutions, only didactical ones, for the design of integrated education and states that the development of integrative educational practices require primarily ethical-political solutions. It is argued that it is essential to link the teaching with the students' real work enhancing their self-organization and requesting transforming of human attitude. From these references, some guidelines for integrated didactic action are systematized, valuing the collective work, the questioning and self-organization as key strategies for the formation of the solidary critical and autonomous subject.
\end{abstract}

Keywords: High school. Integrated teaching. Pedagogical practices. 


\section{La práctica educativa como un reto para la educación integral}

\section{Resumen}

Se tratan, aquí, las prácticas pedagógicas articuladas al proyecto de enseñanza integrado. Por medio de una investigación bibliográfica y teniendo como referencia principal a educadores marxistas, en particular a Pistrak (2009), se problematizan posibles soluciones, apenas didácticas, para el proyecto de enseñanza integrado y se afirma que la implementación de prácticas pedagógicas integradoras requiere, principalmente, soluciones ético-políticas. Se sostiene que lo esencial es vincular la enseñanza al trabajo real de los alumnos, confiriendo importancia a su auto-organización y demandando una actitud humana transformadora. A partir de estas referencias, se sistematizan algunas orientaciones para una acción didáctica integradora, valorando el trabajo colectivo, la problematización y la auto-organización como estrategias principales para la formación de los sujetos solidarios, críticos y autónomos. Palabras llave: Enseñanza media. Enseñanza integrada. Prácticas pedagógicas.

\section{Introdução}

"A verdade é o todo." Com base nessa ideia hegeliana, compreendemos o conteúdo da proposta de ensino integrado e consideramos o desafio de pensar práticas pedagógicas que nos aproximem de uma leitura ampla da realidade, mesmo que reconheçamos a impossibilidade de uma apropriação cognitiva desse "todo."

Essa ideia ganha mais materialidade como referência para o ensino integrado na fala de Franco (2005, p. 18), para quem o sentido que deve ser dado ao ensino integrado é o de "[...] completude, de compreensão das partes no seu todo ou da unidade social [...]", já que é, na totalidade, que os construtos particulares se fazem verdade.

Não apenas uma forma de oferta da educação profissional de nível médio, o ensino integrado é uma proposição pedagógica que se compromete com a utopia de uma formação inteira, que não se satisfaz com a socialização de fragmentos da cultura sistematizada e que compreende como direito de todos ao acesso a um processo formativo, inclusive escolar, que promova o desenvolvimento de suas amplas faculdades físicas e intelectuais. 
Práticas pedagógicas e ensino integrado

Essa forma de compreender o ensino integrado exige a crítica às perspectivas reducionistas de ensino, que se comprometem em desenvolver algumas atividades humanas em detrimento de outras e que, em geral, reservam aos estudantes de origem trabalhadora o desenvolvimento de capacidades cognitivas básicas e instrumentais em detrimento do desenvolvimento de sua força criativa e de sua autonomia intelectual e política.

Ao tratarmos de práticas pedagógicas orientadas pela ideia de integridade da formação humana, sistematizamos algumas indicações teóricas e práticas com o propósito de favorecer aos educadores de ensino médio e técnico, em particular, subsídios que permitam a construção de arranjos pedagógicos promotores da compreensão da dialeticidade entre as especificidades dos diferentes fenômenos físicos e sociais tratados em sala de aula com a totalidade natural e social.

Consideramos a possibilidade de haver práticas pedagógicas mais adequadas ao projeto de ensino integrado, mas recusamos a ilusão de haver uma única forma de promover a integração parte-todo, teoria-prática e ensino técnico e profissional, no ensino médio. Considerar a possibilidade de um único método ser válido para todas as situações de ensino integrado seria um

63 equívoco, pois há uma miríade de procedimentos que, em função da matéria, dos alunos e das finalidades educacionais específicas, podem favorecer a ampliação da compreensão do mundo, como propõe o projeto de ensino integrado.

Nossa maior preocupação foi de abordar questões práticas relativas ao processo didático de experimentação do ensino integrado, à luz de referências identificadas com a chamada pedagogia socialista, e propor indicações orientadoras para o trabalho pedagógico de professores e técnicos educacionais, principalmente.

Assumimos o ensino integrado como proposta não apenas para 0 ensino profissional. $\bigcirc$ ensino integrado é um projeto que traz um conteúdo político-pedagógico engajado, comprometido com o desenvolvimento de ações formativas integradoras (em oposição às práticas fragmentadoras do saber), capazes de promover a autonomia e ampliar os horizontes (a liberdade) dos sujeitos das práticas pedagógicas, professores e alunos, principalmente.

Ademais, não restringimos a ideia de ensino integrado como o conteúdo de uma concepção de ensino médio, apesar de essa concepção ter 
fundamentado uma acertada corrente de educação no Brasil. Tomamos a ideia de integração como um princípio pedagógico orientador de práticas formativas focadas na necessidade de desenvolver nas pessoas /crianças, jovens e adultos) a ampliação de sua capacidade de compreensão de sua realidade específica e da relação desta como a totalidade social.

Assim, utilizamos, neste artigo, a expressão ensino integrado, em vez de ensino médio integrado, pois consideramos que as discussões e indicações feitas aqui servem para compreendermos melhor não apenas o ensino médio ou a educação profissional técnica, mas também toda a educação básica assim como a formação humana em geral.

Consideramos, entretanto, que o desenvolvimento de práticas pedagógicas integradoras não depende, apenas, de soluções didáticas, elas requerem, principalmente, soluções ético-políticas. Ou seja, a definição clara de finalidades políticas e educacionais emancipadoras e o compromisso com elas próprias é condição para a concretização do projeto de ensino integrado, sem o que essa proposta pode ser reduzida a um modismo pedagógico vazio de significado político de transformação.

Nossa tese se baseia no pressuposto de que, no Brasil, "[... as propostas educacionais inovadoras foram aquelas vincadas às lutas por mudanças no projeto societário dominante" (FRIGOTTO, 2010, p. 10). Como ensinava Pistrak (2009), as estratégias de ensino e de organização curricular servem ao projeto de sociedade que assumimos em função de nossa leitura da "realidade atual." Sem isso definido de modo claro, o ensino integrado, como já afirmamos, pode tornar-se, apenas, um projeto didático estéril.

Buscamos organizar algumas indicações possíveis de ser consideradas nas práticas pedagógicas que se querem orientadas pela ideia de ensino integrado e sustentamos que mais importante que a definição antecipada de técnicas de ensino ou de organização curricular, mais ou menos adequadas ao ensino integrado (apesar de isso ser verdadeiro e necessário), é condição para o desenvolvimento de práticas pedagógicas integradoras que os sujeitos do ensino, principalmente, e da aprendizagem revelem uma atitude humana transformadora, que se materialize no seu compromisso político com os trabalhadores e com a sociedade dos trabalhadores, até porque as práticas educativas não se constituem na escola, tampouco têm implicações que se encerram nela. 
Práticas pedagógicas e ensino integrado

Mas, por outro lado, não reduzimos a possibilidade do ensino integrado a um ato de vontade dos docentes e dos gestores educacionais; compreendemos que este depende, também, das condições concretas de sua realização, argumentamos que a promoção de práticas pedagógicas integradoras requer a constituição de um ambiente material que a favoreça e da busca permanente pelo elemento integrador, considerando as realidades específicas, a totalidade social e os sujeitos envolvidos.

\section{Pesquisas sobre o EMI (Ensino Médio Integrado) revelam muitas dificuldades de experimentação de integração}

Várias já foram as experimentações de ensino médio integrado, na história recente da educação brasileira. Em pesquisa realizada em 2011 , Costa (2012) recuperou trinta e seis (36) teses e dissertações que tinham como o objeto o ensino médio integrado. Com base nessas pesquisas, a autora sistematizou alguns dos problemas que dificultam a materialização dessa proposta de ensino. A pesquisadora situa três ordens de problemas na materialização 65 do ensino médio integrado; problemas de ordem conceitual, de operacionalização curricular e de organização dos sistemas de ensino.

Revela ainda que o EMI não foi compreendido como projeto político-pedagógico que se compromete com a formação ampla dos indivíduos. Em geral, o ensino integrado tem sido compreendido apenas como estratégia de organização dos conteúdos escolares, sem relevar ao conteúdo ético-político transformador da proposta ou da materialidade de sua operacionalização. Para Costa (2012), isso dificulta a efetivação da proposta de integração do ensino médio e técnico nas escolas e nos sistemas de ensino.

Em síntese, a implementação do ensino médio integrado dentro de uma instituição não se resume à questão pedagógica, a um projeto curricular de ensino. Requer a superação de diversos desafios dentre eles os de gestão; pedagógicos; condições de ensino; condições materiais; hábitos estabelecidos culturalmente que limitam a formação integrada dos alunos (COSTA, 2012, p. 38).

Apesar das dificuldades, o projeto de ensino integrado não deve ser abandonado, pelo menos enquanto conteúdo, já que representa um projeto 
comprometido com a formação ampla dos trabalhadores e se contrapõe às pedagogias liberais da moda.

Se, por um lado, o ensino integrado tem se revelado de difícil operacionalização; por outro lado, as pedagogias liberais, em geral, não ofereceram possibilidades reais de desenvolverem capacidades amplas e ilimitadas dos trabalhadores, que thes permitam compreender a totalidade social.

$\bigcirc$ ensino integrado aqui é reconhecido como proposta de educação com inspiração na ideia gramsciana de escola unitária, mas que não se confunde com ela já que seus limites de formação integral estão dados pela sociabilidade capitalista contemporânea.

Ao abordar os desafios de desenvolvimento de práticas pedagógicas, sustentamos que uma didática integradora requer, necessariamente, embora de forma não suficiente, uma atitude docente integradora, orientada pela ideia de práxis.

Trata-se, pois, de compreender a ação pedagógica em sua relação com a totalidade das ações humanas que, sempre, tem repercussões éticas e políticas para a vida social, bem como a necessária dependência entre os saberes específicos e locais ao conjunto de saberes sociais. A ação didática integradora ganha sentido assim enquanto ação ético-política de promoção da integração entre os saberes e práticas locais com as práticas sociais globais bem como quando promove a compreensão dos objetos em sua relação com a totalidade social.

ensino integrado é um projeto pedagógico que só pode cumprir com sua finalidade de formar na perspectiva da totalidade se assumir a liberdade como utopia e mantiver íntima vinculação com o projeto político de construção de uma sociabilidade para além do capital.

Por fim, destacamos que, neste artigo, apesar de tratarmos de questões práticas do fazer pedagógico, procuramos evitar a ldeia de normatividade, que implicaria a confecção de um manual orientador do "como fazer." A sua principal motivação foi de fornecer ao educador, principalmente àquele comprometido com o projeto político-pedagógico da integração do ensino, um conjunto de orientações teórico-práticas capaz de orientá-lo a construir suas próprias estratégias de ensino, orientadas pelos fundamentos da Pedagogia do Trabalho. 


\section{Organização do trabalho pedagógico e ensino integrado}

Compreendemos que são várias as possibilidades de arranjos pedagógicos e curriculares que favorecem as práticas pedagógicas orientadas pela ideia de integração e que são diferenciados os elementos de integração do ensino e da aprendizagem. A escolha por um arranjo depende de inúmeras variáveis, tais como: as condições concretas de realização da formação, o conhecimento e a maturidade profissional do professor, o perfil da turma e o tempo disponível, mas, decisivo é o compromisso docente com as ideias de formação integrada e de transformação social.

Apesar de afirmarmos que o ensino integrado não deva ser resumido a um projeto pedagógico, menos ainda a projeto didático ou a um tipo específico de desenho curricular, essas dimensões são verdadeiras e necessariamente devem constituir objeto da preocupação e do labor dos estudiosos e educadores que se assumem comprometidos com emancipação social.

Diferentes são as formas de se pensar os conteúdos necessários à formação de crianças, jovens e adultos capazes de desenvolver a sua capacidade de, autonomamente, interpretar e agir sobre a realidade. Diferentes

67 também são as possibilidades de organizar os conteúdos necessários para tal. Mas o fundamental é o compromisso com a formação ampla dos trabalhadores e a articulação dos processos de formação com o projeto ético-político de transformação social. Considerando esses dois pressupostos, as formas de reorganização curricular devem ser experimentadas e avaliadas, levando em conta que não há uma única forma, tampouco uma forma mais correta que outra para a efetivação de um currículo integrado, mas que elas têm sempre algum impacto sobre a produção/reprodução da sociedade.

currículo, assim como a escola, é espaço de contradição, apesar de reproduzir as estruturas existentes, é " [... correia de transmissão da ideologia oficial $[\ldots]^{\prime \prime}$ e, ao mesmo tempo, uma ameaça à ordem estabelecida por oferecer a possibilidade de contribuir para a libertação (GADOTI, 1992, p. 150). Constitui-se, portanto, em um espaço de luta entre as classes dominantes e as subalternas, refletindo a "[...] exploração e a luta contra a exploração."

Considerado assim, o currículo constitui-se em uma arena política de ideologia, poder e cultura. Consiste em um campo ideológico por transmitir e produzir uma visão de mundo vinculado aos interesses dos grupos sociais, por 
meio das práticas educativas. É um espaço de expressão das relações sociais de poder, visto que se constitui e, ao mesmo tempo, resulta da relação entre as classes sociais; é uma área de conflitos de cultura de classes, em que se transmite a cultura oficial e se produz a cultura contestada. Portanto, é considerado um conjunto de ações políticas, determinadas social e historicamente (SILVA; MOREIRA, 2005).

A educação escolar brasileira tem a sua organização curricular, no Brasil, marcada por formas curriculares instrumentais e promotoras de um tipo humano conformado, política e pedagogicamente. A Pedagogia das Competências, que assumiu centralidade, nas formulações educacionais oficiais na década de 1990, inspirada na Filosofia Pragmática, tinha na utilidade prática o critério para a definição e a organização dos conteúdos formativos.

Assim, os desenhos curriculares organizados com base nesse critério recorriam aos saberes, habilidades e atitudes apenas na medida da possibilidade de promoverem alguma capacidade específica requerida pelo mercado. Aquilo que não se revelasse imediatamente útil não deveria ser incorporado nos currículos.

Na perspectiva da integração, a utilidade dos conteúdos passa a ser concebida não na perspectiva imediata do mercado, mas tendo como referência a utilidade social, ou seja, os conteúdos são selecionados e organizados na medida de sua possibilidade de promover comportamentos que promovam o ser humano e instrumentalizem o reconhecimento da essência da sociedade e a sua transformação. Procura-se, com isto, formar o indivíduo em suas múltiplas capacidades: de trabalhar, de viver coletivamente e agir autonomamente sobre a realidade, contribuindo para a construção de uma sociabilidade de fraternidade e de justiça social.

A seleção e organização dos conteúdos formativos na perspectiva do projeto de ensino integrado requerem, portanto, a superação das pedagogias de conteúdo liberal, como a Pedagogia das Competências. Machado entende assim o currículo integrado:

É a concepção e a experimentação de hipóteses de trabalho e de propostas de ação didática que tenham, como eixo, a abordagem relacional de conteúdos tipificados estruturalmente como diferentes, considerando que esta diferenciação não pode, a rigor, ser tomada como absoluta ainda que haja especificidades que devem ser reconhecidas. Com relação ao objeto deste artigo, são os conteúdos 
classificados como gerais ou básicos e os conteúdos nomeados como profissionais ou tecnológicos (MACHADO, 2009, p. 2).

Alguns princípios podem ser orientadores para a organização de um currículo integrado: a contextualização, a interdisciplinaridade e o compromisso com a transformação social.

A contextualização pressupõe, na perspectiva aqui trabalhada, a íntima articulação dos conteúdos formativos com a realidade social e com os projetos políticos dos trabalhadores e de suas organizações sociais. Pistrak (2009) compreendia que a realidade social se constituiria como ponto de partida para os currículos integrados e a realidade social transformada como ponto de chegada.

A interdisciplinaridade é compreendida como o princípio da máxima exploração das potencialidades de cada ciência, da compreensão dos seus limites, mas, acima de tudo, como o princípio da diversidade e da criatividade (ETGES apud BIANCHETTI; JANTSCH, 1995). Para esse autor, a interdisciplinaridade não toma a fragmentação disciplinar como uma patologia. Esse conceito de interdisciplinaridade pressupõe que é, na totalidade dinâmica, que

69 os construtos particulares se fazem verdade. Para Pistrak (2009), a dificuldade da ação interdisciplinar é que cada disciplina toma seus objetivos específicos como os mais importantes, em vez de subordinar-se a um objetivo geral já que, na escola, cada "[...] ciência deve ser ensinada apenas como meio de conhecer e de transformar a realidade de acordo com os objetivos gerais da escola" (PISTRAK, 2009, p. 1 19).

compromisso com a transformação social revela a teleologia do projeto de ensino integrado. É esse princípio que distingue a práxis marxista da filosofia pragmática que busca vincular os processos formativos com demandas imediatas e pontuais. Dewey (1936, p. 147), filósofo pragmático que propôs o progressivismo educacional, via como impossível "[...] a associação entre processos formativos com ideias de um futuro distante" e subordinava os conteúdos de ensino ao imediato, dando-lhes um sentido prático utilitário, promovendo a conformação. Na perspectiva aqui assumida (marxista), a ação pedagógica é tomada como ação material, que subordina os conteúdos formativos aos objetivos de transformação social, visando à produção, portanto, da emancipação. Em tal perspectiva, a ação (pedagógica) material corresponde a "[...] interesses sociais e que, considerada do ponto de vista histórico-social, 
não é apenas produção de uma realidade material, mas sim criação e desenvolvimento incessantes da realidade humana" (VÁZQUEZ, 1968, p. 213).

Tendo como referência as ideias de contextualização, interdisciplinaridade e teleologia, propomos pensar as estratégias de organização dos conteúdos, na perspectiva do ensino integrado.

\section{Problematização, trabalho cooperativo e auto-organização como possibilidades de procedimentos de ensino integrado}

É necessário enfrentar também o desafio de pensar estratégias de organização curricular e de ensino que favoreçam a superação da visão fragmentária e linear da realidade e tornem mais possível um projeto de formação orientado pela ideia de integração. Tal desafio metodológico é colocado em termos políticos por Frigotto.

Em relação ao método o confronto é entre a visão fragmentária e linear da realidade que concebe a totalidade como soma das partes e a concepção dialética-histórica ou materialista histórica, cujo fundamento é buscar entender quais as determinações ou mediações que produzem determinada realidade humana. Aqui a totalidade resulta da relação das partes (FRIGOTTO, 2012, p. 08).

Defendemos, porém, que não é a escolha pelas técnicas de ensino que garante essa compreensão da dialeticidade do mundo. Mais importantes são os compromissos que assumimos e que nos permitem fazer escolhas e, dentro dos limites objetivos colocados pela realidade das escolas brasileiras, ressignificar procedimentos tendo em vista os objetivos de emancipação social e de promoção da autonomia dos sujeitos.

Para considerar as estratégias de ensino, partimos da compreensão de que a ação didática também se coloca como um objeto da disputa hegemônica entre capital e trabalho. Essa disputa revela-se nas diferentes perspectivas que assume. Para Candau (1995), a Didática tem sido entendida ora sob uma perspectiva dicotômica e ora sob a perspectiva da unidade. A visão dicotômica que separa teoria e prática se revela de duas formas: a) na perspectiva dissociativa, que separa, mecanicamente, os elementos, isolando-os e 
Práticas pedagógicas e ensino integrado

confrontando-os (percepção vulgar); e b) Na perspectiva associativa (positivo-tecnológica), que separa os polos sem oposição.

Nessa visão, a prática é uma aplicação da teoria (percepção de uma relação mecânica de dependência). Na visão dicotômica (associativa), reduz-se a teoria à simples organização, sistemática e hierárquica das ideias e estabelece-se uma relação hierárquica autoritária de mando e obediência la teoria determina a prática ou, inversamente, a prática exige e a teoria se faz útil). Essa visão predomina nas práticas de educação profissional que reproduzem a dualidade educacional brasileira.

A didática pode ser entendida também enquanto ação de articulação entre a teoria e a prática. Essa articulação tem sido pensada, no entanto, de diferentes maneiras: a) por justaposição, b) com subordinação de um elemento a outro (da prática sobre a teoria ou da teoria sobre a prática) ou c) sob a perspectiva da unidade indissolúvel (CANDAU, 1995).

Sob a ótica da unidade, a distinção entre teoria e prática se dá no seio de uma unidade indissolúvel que pressupõe uma relação de autonomia e dependência de um termo em relação ao outro. Na visão de unidade, a teoria nega a prática imediata para revelá-la como práxis social, a prática nega a teoria como um saber autônomo, como puro movimento de ideias e a teoria e prática são tidos como dois elementos indissolúveis da "práxis", definida como atividade teórico-prática. Seria essa perspectiva de unidade da relação entre teoria e prática que orientaria os projetos de ensino integrado.

No atual debate acerca da educação profissional e, especificamente, acerca de uma didática da educação profissional, tem sido muito presente a visão dicotômica que pode ser entendida, por exemplo, na separação e distinção entre profissionalização e escolarização (visão dissociativa) ou como a "soma" da profissionalização com a escolarização. Essa visão dicotômica também se revela na separação entre as disciplinas teóricas e as disciplinas práticas, entre os saberes que desenvolveriam o pensar e outros que desenvolveriam as capacidades de fazer. Outra perspectiva, fundada na ideia de unidade, pressupõe a indissolubilidade entre teoria e prática.

Considerando uma possível didática da educação profissional, a perspectiva integradora deve pressupor:

- $O$ compromisso com a formação ampla e duradoura dos homens, em suas amplas capacidades. 
- A ideia de práxis como referência às ações formativas.

- Que a teoria e a prática educativa constituam o núcleo articulador da formação profissional.

- A teoria sendo sempre revigorada pela prática educativa.

- A prática educacional sendo o ponto de partida e de chegada.

- A ação docente se revelando na prática concreta e na realidade social.

Tomamos as técnicas de ensino tal como concebe Araujo (1991), como mediações das relações entre o professor e o aluno, projetadas como condições necessárias e favoráveis, mas não suficientes do processo de ensino. As técnicas de ensino assim compreendidas estão sempre subordinadas, política e metodologicamente, às suas finalidades e às práticas sociais que as conformam.

Também concordamos com Araujo (1991) quando este defende que as técnicas podem estar a serviço da manipulação, do tecnicismo, da Escola Nova ou da perspectiva libertadora. Sendo assim, torna-se possível pensar e realizar um estudo dirigido sem a auréola planificante que o definia, assim como também torna-se possível a aula expositiva sem as características do ensino tradicional. Qualquer técnica, portanto, compreendida como mediação, deve ser reconhecida em seus limites e sem a certeza de que seja garantia de sucesso do ensino e da aprendizagem na formação de amplas capacidades humanas.

Como "meio", a técnica sempre serve a um fim e é nessa perspectiva que são tratadas aqui as estratégias de ensino, em articulação com um projeto educacional integrador e emancipador. Sua validade também só pode ser avaliada se considerados os seus fins e a sua prática já que é o exercício da técnica que a valida e não o seu prévio conhecimento teórico.

A possibilidade de ressignificação de diferentes procedimentos de ensino não significa, porém, a afirmação de uma possível neutralidade dos mesmos. Estes têm origem e têm história que revelam o seu uso e os seus efeitos. Mesmo assim, eles constituem um conjunto de possibilidades que, considerando as finalidades de emancipação e as condições objetivas, podem favorecer mais ou menos ao desenvolvimento da formação ampla dos indivíduos.

As diferentes possibilidades de procedimentos de ensino favorecem mais ou menos o projeto de ensino integrado quando são organizados para 
Práticas pedagógicas e ensino integrado

promover a autonomia, por meio da valorização da atividade e da problematização, e para cultivar o sentimento de solidariedade, mediante do trabalho coletivo e cooperativo.

\section{a) Valorização da atividade e da problematização como estratégias de promoção da autonomia}

A valorização da atividade (de docentes e discentes) nos processos formativos é necessária para a efetivação de projetos integradores de ensino, mas não distingue uma pedagogia de base social. $\bigcirc$ conceito Pedagogia Ativa é hoje polissêmico já que ele ajuda a caracterizar tanto projetos que visam à transformação quanto projetos que visam à conformação social.

A pedagogia deweyana, de cunho liberal, também se caracterizava como uma pedagogia ativa. Ela, afinal, surgiu da recusa dos educadores à pedagogia tradicional, que operava contando com a passividade dos alunos e, em certa medida, também dos docentes.

Mas, então, o que distingue a ideia de atividade para as pedagogias

73 de cunho liberal, como a Pedagogia das Competências, das pedagogias de base social, como o EMI? Evidentemente que é o compromisso com a transformação social, tal como expresso anteriormente, para que essa atividade tenha como função desenvolver nos estudantes a sua capacidade de agir crítica e conscientemente e de adaptar a realidade às suas necessidades e não o oposto, de desenvolver a sua capacidade de adaptação às diferentes situações colocadas pela vida cotidiana. Para Pistrak:

Somente na atividade pode a criança formar-se para ser ativa, somente na ação aprende a agir, Somente na realidade [...] aprende a participar conscientemente, do mesmo modo, no trabatho que diz respeito às formas da ordem estatal e mundial (PISTRAK, 2009, p. 131, grifo nosso).

A atividade, portanto, na perspectiva da transformação da realidade e visando à ampliação das capacidades humanas, coloca-se como um componente a ser considerado no planejamento, no desenvolvimento e na avaliação das práticas pedagógicas que se querem integradora. 
A autonomia, condição desejável pelo ensino integrado, é aqui entendida como capacidade de os indivíduos compreenderem a sua realidade, de modo crítico, em articulação com a totalidade social, intervindo na mesma conforme as suas condições objetivas e subjetivas. Em outras palavras, reconhecendo-se como produto da história, mas também como sujeito de sua história.

A ideia de autonomia também pode ser identificada com a defesa da auto-organização dos estudantes feita por Pistrak (2009). Para o educador soviético, a auto-organização (autodireção) dos estudantes revelar-se-ia em três capacidades:

a. Habilidade de trabalhar coletivamente.

b. Habilidade de trabalhar organizadamente cada tarefa.

c. Desenvolvimento da capacidade criativa.

Para Pistrak, a tarefa de promover a auto-organização dos estudantes exige que estes passem "[...] por uma variedade de formas organizacionais, o que pode ser conseguida dando-se à auto-organização formas mais flexíveis, que se adaptem cada vez às novas tarefas" (PISTRAK, 2009, p. 123). Pressupõe autodireção e criatividade.

A força criativa desenvolve-se, principalmente, por meio de estratégias de problematização da realidade e dos conteúdos escolares, suscitando a busca por ferramentas, teóricas e práticas, capazes de auxiliar os indivíduos no enfrentamento de suas tarefas cotidianas e históricas.

Assim como em relação aos estudantes, cabe aos projetos educacionais integradores reconhecerem, também, a necessária autonomia docente. Ambos, professores e estudantes, são os sujeitos da prática pedagógica. Se a função do principal do educador é mediar a relação entre cultura elaborada e o educando, dando direção à aprendizagem, este exercício só terá possibilidades de produzir a autonomia discente e o reconhecimento da realidade social se orientada por um projeto político-pedagógico de transformação da realidade. 


\section{b) Trabalho colaborativo como estratégia de trabalho pedagógico}

Se o horizonte de projetos integrados de ensino, na perspectiva da Escola Unitária, é a construção de uma sociedade de iguais, fraterna e solidária, cabe aos procedimentos pedagógicos cultivarem os valores que promovam essa solidariedade. É preciso, pois, que o trabalho escolar valorize, ao máximo, toda forma de trabalho coletivo e colaborativo.

Para Pistrak (2000), o trabalho coletivo corresponde a uma tarefa coletiva entendida como uma unidade, ou seja, requer a responsabilidade coletiva pelo trabalho. Para esse educador soviético, é o trabalho coletivo que revela a essência da escola socialista, tornando-se uma categoria central da sua proposta de pedagogia. $\bigcirc$ coletivo é entendido, por ele, não como a negação simples do indivíduo ou de sua individualidade, mas como crítica às práticas individualistas.

Freitas (2009) vê em Pistrak a distinção entre individualidade e individualismo assim como entre coletivo de coletivismo, que seria a forma equivocada da vida coletiva. Pistrak (2009) critica, ferozmente, o "egocentrismo" que seria promovido pelas teorias pedagógicas liberais já que para estas cada 75 aluno responde por si.

Na operacionalização do ensino integrado, práticas pedagógicas que priorizem o trabalho coletivo, ao invés do trabalho individual devem, portanto, ser valorizadas, sem que isso signifique o abandono de estratégias de ensino e de aprendizagem individualizadas. Neste caso, entretanto, estas devem ser compreendidas como momentos intermediários para o trabalho coletivo de ensinar e de aprender.

\section{Considerações conclusivas: sobre os procedimentos de ensino que favorecem a integração}

Várias são as possibilidades de estratégias de ensino e nenhuma delas pode ser descartada a priori, seja por razões ideológicas ou por uma possível impossibilidade de eficácia. Sendo assim, reafirmamos que cada procedimento de ensino, enquanto meio, poder servir, mais ou menos, para o desenvolvimento de práticas integradoras. 
Aulas expositivas, estudo do meio, jogos didáticos, visitas técnicas Integradas, seminários, estudo dirigido, oficinas e várias outras estratégias de ensino e aprendizado podem servir tanto para projetos conservadores, tradicionais, conformadores das capacidades humanas, quanto para projetos libertários, comprometidos com a ampliação das capacidades humanas.

Procuramos considerar diferentes possibilidades metodológicas para a experimentação do projeto de ensino integrado e sustentamos que não existe uma única técnica mais adequada para a implementação do ensino integrado pois considerar essa possibilidade seria sucumbir a um determinismo metodológico.

Também sustentamos a possibilidade de ressignificação das técnicas e estratégias de ensino e de aprendizagem. Sem considerarmos a possibilidade de sua neutralidade, já que todas as técnicas têm história e os contextos nos quais foram geradas deram-lhe conteúdo, compreendemos que o que define o caráter (ético-político-pedagógico) às estratégias de ensino são as finalidades que orientam sua escolha, seu uso e sua avaliação. Desse modo, práticas pedagógicas que se querem integradoras, orientadas pela ideia de emancipação social e de desenvolvimento da autonomia e da capacidade criativa dos estudantes, cumprem melhor ou pior suas finalidades quanto mais articuladas aos projetos da classe trabalhadora e de suas organizações, quanto mais abarcar a dinâmica das relações sociais; afinal, a prática pedagógica ultrapassa o espaço escolar.

As técnicas e procedimentos têm características comuns, independentes de seu uso. Todas devem ser entendidas como meio para os processos de ensino e de aprendizagem, todas pressupõem um plano de estudo/trabalho e todas requerem ações de avaliação para verificação de sua efetividade, no entanto, são os princípios que as orientam que determinam o caráter unitário ou fragmentário da proposta.

A atitude docente integradora, tratada anteriormente, parece ser também fator decisivo à construção de práticas pedagógicas de integração, já que supõe um compromisso com a transformação social e a recusa à lógica pragmática, que hegemoniza as políticas e os projetos educacionais hegemônicos no Brasil.

A ideia de integração não caracteriza, por si, uma pedagogia que visa à transformação, iá que várias são as pedagogias que propõem integrar 
trabalho e educação. A Pedagogia das Competências, por exemplo, tomou essa integração como uma de suas principais promessas, mas fazia isso presa à realidade dada, ou seja, o seu conteúdo pragmático the impunha pensar essa integração visando ao ajustamento da formação humana às demandas específicas e pontuais do mercado de trabalho, diferente da integração proposta pelo projeto hoje identificado como Ensino Médio Integrado, que compreende essa integração sendo amalgamada pela ideia de transformação da realidade social.

A articulação entre trabalho e ensino deve servir para formar homens onilaterais, ou seja, promover e desenvolver amplas capacidades humanas, intelectuais e práticas. Assim, o trabalho coloca-se como princípio educativo somente quando compreendido na perspectiva da revolução social. Compreendê-lo, apenas, na sua perspectiva pedagógica, seria, portanto, um equívoco.

\section{Notas}

1 Optamos pelo termo experimentação por considerá-lo mais adequado para explicar o momento em que diferentes instituições escolares, estatais ou não, buscam fazer do ensino integrado uma "pedagogia em ação." As expressões operacionalização ou implementação, por exemplo, pressupõem que já exista um modelo ideal ou mesmo um conjunto de orientações didáticas orientadoras do trabalho pedagógico para o ensino integrado. A realidade tem mostrado que, nessas unidades escolares, existem mais experimentações que realizações propriamente ditas.

2 Em artigo recente, Araujo e Rodrigues (2012) defenderam a tese de que a ação docente referenciada no projeto de ensino integrado requer, mais que a escolha de técnicas adequadas, 0 compromisso ético-político do educador para se concretizar em sala de aula, além das condições materiais necessárias.

3 De diferentes maneiras, Lobato (2010), Mendonça (2012) e Barros (2008) recuperam diferentes acepções e usos para as propostas de educação articuladas às ideias de integração, integralidade e educação integral no Brasil.

4 Sobre os limites da Pedagogia das Competências, em função de sua referência no pragmatismo e no utilitarismo ver Araujo (2001), sobre os limites da Pedagogia das Competências em função de sua base construtivista ver Ramos (2001). Ambos os estudos, resultantes de teses de doutoramento, problematizam o conteúdo liberal da Pedagogia das Competências e a sua insuficiência para a promoção de sujeitos autônomos e trabalhadores amplamente qualificados.

5 Também identificada por esse autor como autodireção. 


\section{Referências}

ARAUJO, José Carlos Souza. Para uma análise das representações sobre as técnicas de ensino. In: VEIGA, Ilma Passos de Alencastro (Org.). Técnicas de ensino: por que não? São Paulo: Papirus, 1991.

ARAUJO, Ronaldo Marcos de Lima. Desenvolvimento de competências profissionais: as incoerências de um discurso. 2001. 218f. Tese (Doutorado em Educação) - Programa de Pós-Graduação em Educação, Universidade Federal de Minas Gerais. Belo Horizonte, 2001.

ARAUJO, Ronaldo Marcos de Lima; RODRIGUES, Doriedson do Socorro. Filosofia da práxis e ensino integrado: uma questão ético-política. In: OLIVEIRA, Ramon (Org.). Jovens, ensino médio e educação profissional. São Paulo: Papirus, 2012.

BARROS, Kátia de Oliveira. A escola de tempo integral como política pública educacional: a experiência de Goianésia (2001-2006). 2008. 205f. Dissertação (Mestrado em Educação) - Programa de Pós-Graduação em Educação, Universidade de Brasília, Brasília, 2008.

JANTSCH, Ari Paulo; BIANCHETTI, Lucídio. Interdisciplinariedade. Petrópolis: Vozes, 1995.

CANDAU, Vera Maria. Rumo a uma nova didática. Petrópolis: Vozes, 1995.

COSTA, Ana Maria Rayol da. Integração do ensino médio e técnico: Percepções de alunos do Instituto Federal de Educação, Ciência e Tecnologia do Pará - IFPA/Campus Castanhal. 2012. $118 f$. Dissertação (Mestrado em Educação) - Programa de Pós-Graduação em Educação, Universidade Federal do Pará, Belém, 2012.

DEWEY, John. Democracia e educação. São Paulo, Companhia Editora Nacional, 1936.

FRANCO, Maria Ciavatta. A Formação Integrada: a escola e o trabalho como lugares de memória e de identidade. In: FRIGOTTO, Gaudêncio; CIAVATTA, Maria; RAMOS, Marise (Org.). Ensino médio integrado: concepções e contradições. São Paul: Cortez, 2005.

FREITAS, Luiz Carlos, A luta por uma pedagogia do meio: revisitando o conceito. In: PISTRAK (Org.). A escola-comuna. São Paulo: Expressão Popular, 2009.

FRIGOTTO, Gaudêncio. Qualidade e quantidade da educação básica no Brasil: concepções e materialidade. Rio de Janeiro, 2012. (Texto impresso). 
Práticas pedagógicas e ensino integrado

Trabalho e formação docente, contexto histórica e política na América Latina. In: OLIVEIRA, Dalila Andrade; MARTINÉRZ, Deolinda (Org.). Nuevas regulaciones educativas en América Latina. Experiencias y subjetividad. Lima (Perú): Fondo Editorial, 2010.

GADOTTI, Moacir. Concepção dialética da educação. 8 ed. São Paulo: Cortez/Autores Associados, 1992.

LOBATO, Deusa de Nazaré Martins. Didática da educação profissional no SENAI-PA Belém, 2010. 137f. Dissertação (Mestrado em Educação) - Programa de Pós-Graduação em Educação, Universidade Federal do Pará, Belém-PA, 2010.

MACHADO, Lucília Regina de Souza. Ensino médio e técnico com currículos integrados: propostas de ação didática para uma relação não fantasiosa. In: MOLL Jaqueline (Org.). Educação profissional e tecnológica no Brasil contemporâneo: desafios, tensões e possibilidades. Porto Alegre: Artmed, 2009.

MENDONÇA, Ana Waleska Pollo Campos. $\bigcirc$ ensino profissional no Brasil: contribuições das pesquisas sobre a história das instituições escolares. In: ARAUJO, Ronaldo Marcos de Lima Araujo; RODRIGUES, Doriedson do Socorro (Org.). A pesquisa em trabalho, educação e políticas educacionais. Campinas: Alínea, 2012.

79 PISTRAK (Org.). A escola-comuna. São Paulo: Expressão Popular, 2009.

RAMOS, Marise. A Pedagogia das competências: autonomia ou adaptação?. São Paulo: Cortez, 2001.

SILVA, Tomáz Tadeu; MOREIRA, Antônio Flávio. Currículo, cultura e sociedade. São Paulo: Cortez, 2005.

VÁZQUEZ, Adolfo Sánchez. Filosofia da Práxis. Rio de Janeiro: Paz e Terra, 1968.

Prof. Dr. Ronaldo Marcos de Lima Araujo Universidade Federal do Pará Instituto de Ciências da Educação | ICED Programa de Pós-Graduação em Educação Grupo de Estudos e Pesquisas sobre Trabalho e Educação | GEPTE Pesquisador produtividade do CNPq E-mail | rlima@ufpa.br 
Prof. Dr. Gaudêncio Frigotto Universidade do Estado do Rio de Janeiro Faculdade de Educação Programa de Pós-Graduação em Educação Grupo Projetos Integrados de Pesquisa em Trabalho, História, Educação e Saúde | THESE Pesquisador produtividade do CNP

E-mail | gfrigotto@globo.com

Recebido 22 abr. 2015

Aceito 2 jun. 2015 